\title{
Feasibility and Safety of Endoscopic Submucosal Dissection of Esophageal or Gastric Carcinomas under General Anesthesia
}

\author{
Qiu-Hua Rong $^{\mathrm{a}}$ Guo-Li Zhao ${ }^{\mathrm{a}}$ Jia-Ping Xie ${ }^{\mathrm{a}}$ Le-Xin Wang ${ }^{\mathrm{b}}$ \\ aLiaocheng People's Hospital of Taishan Medical University, Liaocheng, P.R. China; bSchool of Biomedical Sciences, \\ Charles Sturt University, Wagga Wagga, N.S.W., Australia
}

\section{Key Words}

Endoscopic mucosal dissection • Endoscopy $\cdot$ General anesthesia $\cdot$ Esophageal cancer $\cdot$ Gastric cancer

\begin{abstract}
Objective: To investigate the feasibility and safety of endoscopic submucosal dissection (ESD) of esophageal or gastric carcinomas under general anesthesia. Subjects and Methods: ESD removal of esophageal or gastric carcinomas was performed in 59 patients under midazolam sedation (control group), and in 46 patients under general anesthesia (GA group). The procedural times, perioperative complications and patient's satisfaction with the procedures were recorded. Results: There was no statistically significant difference in age ( $65 \pm 12$ vs. $58 \pm 11$ ), male gender (43.5 vs. $49.2 \%)$, types or location or the size of the carcinomas ( $30 \pm 6 \mathrm{vs} .28$ $\pm 7 \mathrm{~mm}$ ) between the control and GA groups $(p>0.05)$. The mean procedural time in the GA group was shorter than in the control group ( $42.5 \pm 5.5$ vs. $79.0 \pm 13.2 \mathrm{~min}, \mathrm{p}=0.01)$. The combined gastric perforation and postprocedural bleeding rate in the GA group was lower than in the control group, but the difference did not reach statistical significance $(p=0.06)$. In the GA group, all patients rated the procedural experience as satisfactory, while in the control group,
\end{abstract}

\section{KARGER}

E-Mail karger@karger.com www.karger.com/mpp

\section{(c) 2012 S. Karger AG, Basel} 1011-7571/13/0223-0280\$38.00/0

Karger

0 pen access

This is an Open Access article licensed under the terms of the Creative Commons Attribution-NonCommercial-NoDerivs 3.0 License (www.karger.com/OA-license), applicable to the online version of the article only. Distribution for non-commercial purposes only.
$38(64.5 \%)$ rated the experience as satisfactory $(p=0.001)$. Conclusion: ESD under general anesthesia was associated with a shorter procedure time and a high rate of patient's satisfaction with the procedures.

Copyright $\odot 2012$ S. Karger AG, Basel

\section{Introduction}

Gastric and esophageal carcinomas are common types of gastrointestinal tumors [1]. Endoscopic submucosal dissection (ESD) of early gastrointestinal carcinomas is a minimally invasive technique for cancer treatment. ESD allows en bloc resection of the entire lesion, permitting a higher curative resection rate and increased quality of life by minimizing the resection size compared with endoscopic mucosal resection (EMR) $[2,3]$. A recent metaanalysis showed that ESD is more effective than EMR for en bloc resection, complete resection, or curative resection [4]. In most previous reports, ESD was performed in a way similar to endoscopic examinations when patients were awake. Because the procedural time for ESD is longer than that for diagnostic endoscopy, and meticulous control of the devices is essential during the procedure, sedation is sometimes required in order to reduce the dis-
Prof. Lexin Wang

School of Biomedical Sciences

Charles Sturt University

Wagga Wagga, NSW 2678 (Australia)

E-Mail lwang@csu.edu.au 
comfort of the patients during the procedures. Several types of intravenous sedatives, such as midazolam, propofol or dexmedetomidine hydrochloride have been tried in patients undergoing ESD for gastrointestinal tumors $[5,6]$. However, it is unclear if ESD performed under general anesthesia is feasible or safe. It is also known that ESD under general anesthesia may improve patient satisfaction with the procedures. In this study, we investigated the feasibility and safety of ESD for early esophageal or gastric carcinoma under general anesthesia.

\section{Subjects and Methods}

\section{Study Design and Patient Selection}

This was a prospective clinical study approved by the Institutional Review Board of our hospital. Written informed consent was obtained from all study participants. Between October 2009 and April 2011, consecutive patients were recruited into this study for ESD removal of early esophageal or gastric cancers. In the first stage of this study (control group), the ESD procedures were performed when patients were sedated with intravenous diazepam $(10 \mathrm{mg})$ administered $10 \mathrm{~min}$ before the commencement of the procedures. In the second stage of the study, ESD was performed under general anesthesia (GA group). At each stage we aimed at 60 patients but the second stage of the study was terminated prematurely as the results based on the first 46 patients in the GA group had reached statistical significance. One of the 60 patients enrolled in the control group was excluded from the final analysis due incomplete survey questionnaire. In the end, this study consisted of 59 patients in the control group and 46 patients in the GA group. The general characteristics of these patients are listed in table 1.

The selection criteria for ESD were: (a) early esophageal or gastric cancer diagnosed through a previous endoscopic biopsy and histopathological examination; (b) lesions confined to the mucosa with no signs of metastasis or local lymph node involvement, and (3) the size of the lesion $<20 \mathrm{~mm}$. Exclusion criteria were: (a) esophageal or gastric cancerous lesions that did not meet the selection criteria, and (b) past or current respiratory, cardiovascular or respiratory disease, renal failure, liver disease or coagulation disorders.

\section{Surgical Methods}

All ESDs were performed in the endoscopy laboratory using an Olympus gastroscope (GIF-XQ260) by a single operator (J.P.X.), who had performed $>100$ ESD procedures before this study. In the GA group, general anesthesia was induced with midazolam and propofol in the endoscopy laboratory, and was maintained with intravenous propofol $(6 \mathrm{mg} / \mathrm{kg} / \mathrm{h})$, fentanyl $(4-8 \mu \mathrm{g} / \mathrm{kg} / \mathrm{h})$ and intermittent vecuronium administration during the procedure. Patients were intubated by an anesthetist and the ventilation rate was maintained at $10-12$ breaths $/ \mathrm{min}$. When the procedure was completed, intravenous infusion of propofol and fentanyl was discontinued, and patients were extubated in the endoscopy laboratory before being discharged to the wards for postprocedural observation for $24-48 \mathrm{~h}$.

ESD under General Anesthesia
Table 1. General characteristics and clinical outcomes of treatment

\begin{tabular}{llll}
\hline & $\begin{array}{l}\text { GA } \\
(\mathrm{n}=46)\end{array}$ & $\begin{array}{l}\text { Control } \\
(\mathrm{n}=59)\end{array}$ & $\mathrm{p}$ \\
\hline Age & $65 \pm 12$ & $58 \pm 11$ & 0.116 \\
$\quad$ Range & $42-80$ & $42-68$ & \\
Male sex & $20(43.5)$ & $29(49.2)$ & 0.694 \\
Gastric cancer & $30(65.2)$ & $36(61.1)$ & 0.689 \\
Esophageal cancer & $16(34.8)$ & $23(38.9)$ & 0.688 \\
Diameter of the tumor, mm & $30 \pm 6$ & $28 \pm 7$ & 0.466 \\
$\quad$ Range & $22-41$ & $21-43$ & \\
Duration of operation (min) & $42.5 \pm 5.5$ & $79.0 \pm 13.2$ & 0.010 \\
Complete removal & $45(97.8)$ & $47(81.0)$ & 0.001 \\
Postprocedural bleeding & $1(2.2)$ & $7(11.9)$ & 0.077 \\
Gastric perforation & $1(2.2)$ & $3(5.1)$ & 0.629 \\
Postprocedural hospital stay & & & \\
$\quad$ days & $1.3 \pm 0.6$ & $2.6 \pm 1.1$ & 0.03 \\
Cancer recurrence & 0 & $2(3.5)$ & 0.503 \\
\hline
\end{tabular}

Figures in parentheses are percentages.

Once the lesions were identified by the endoscopic examination, $8-10 \mathrm{ml}$ indigo carmine was used to stain and mark the lesions on the surface (fig. 1). The margin of the lesions was carefully marked by the snare wire of the APC 300EA endoscope argon scalpel. Normal saline premixed with methylene blue and epinephrine was injected to the lesions until the lesions were clearly elevated. A circumferential incision was made around the lesions with hook knives and submucous tissues were separated. The mucosa, including the target lesion, was strangulated by the snare wire, and was subsequently removed (fig. 1). Any bleeding in the wound was stopped by electrocautery or by a hemostasia clip.

The procedural times, which were defined as the duration between the insertion of the endoscope and the removal of the lesions and withdrawal of the endoscope, were recorded.

\section{Assessment of Procedural Satisfaction among the Patients}

Patient's satisfaction with the ESD procedures was assessed before hospital discharge, using a simple visual analogue scale. The scale has 11 options from 0 (most unsatisfactory) to 10 (most satisfactory), largely reflecting the pain or discomfort associated with the procedure. Patients were encouraged to select one of the options on the scale to reflect their experiences with the procedure itself, but not the pre- or postprocedural care or outcomes. We arbitrarily defined a rating scale of more than 5 as satisfactory, and 5 or less as unsatisfactory.

\section{Follow-Up}

Patients were followed up in the outpatient clinics monthly in the first 3 months, then bimonthly for a total of 12 months. Endoscope examination was performed 1, 3 and 12 months following the ESD, unless there were signs of tumor recurrence or other complications, for which endoscopic examination was performed immediately to confirm the diagnosis. 
Fig. 1. a-c Removal of an esophageal tumor by ESD, before (a) and during (b) the procedure. c Removed esophageal lesion. d-f Removal of a gastric lesion by ESD, before (d) and during (e) the procedure. $\mathbf{f}$ Removed gastric lesion.
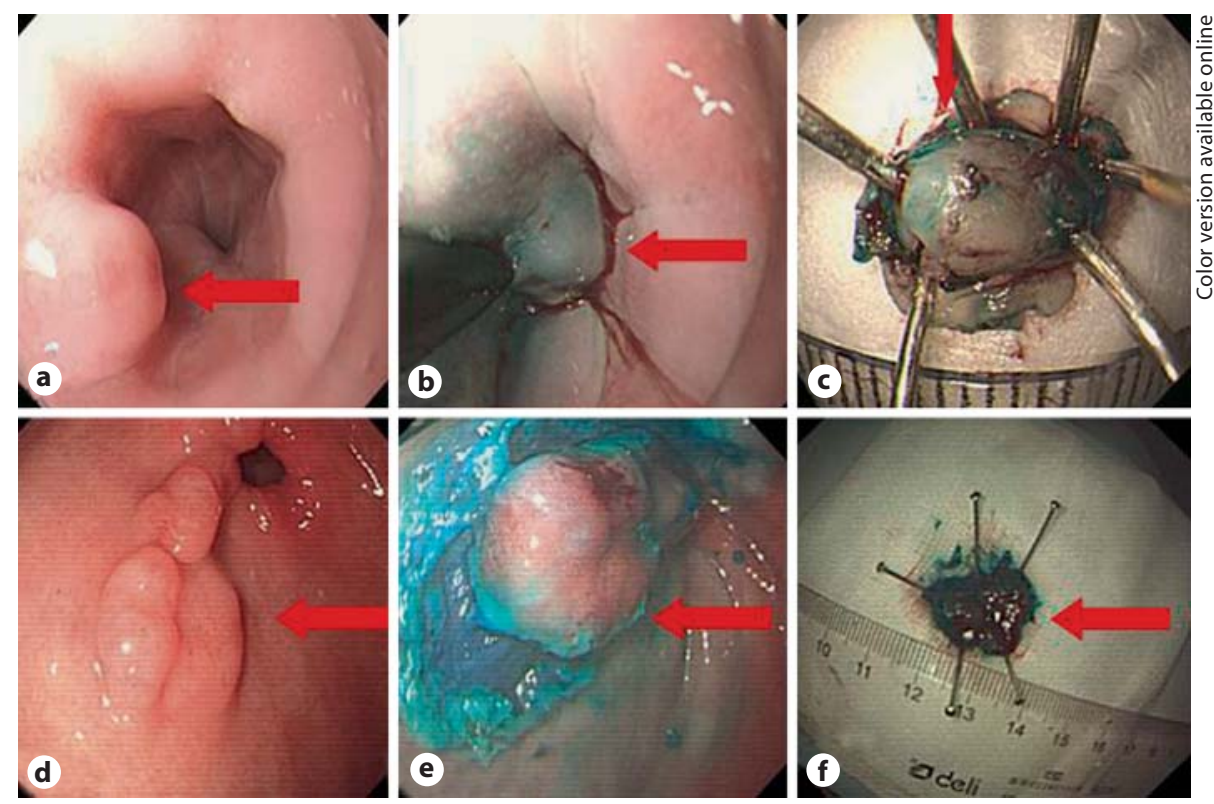

Statistical Analysis

Continuous variables are expressed as mean \pm SD. Differences between groups were compared by one-way ANOVA. Categorical variables were compared by Fisher's exact test; $\mathrm{p}$ value $<0.05$ was considered statistically significant. All statistical analysis was performed with SPSS v13.0 software package (version 13.0, Chicago, Ill., USA).

\section{Results}

\section{General Findings}

Of the 105 patients, 25 (23.8\%) had poorly differentiated adenocarcinoma infiltrating the muscularis mucosa. Thirty-seven (35.2\%) had severe dysplasia, and 43 (41.0\%) had flat elevated lesions. The diameter of the lesions ranged from 22 to $41 \mathrm{~mm}$ (median, $28 \mathrm{~mm}$ ). In 24 (22.9\%) patients the lesion was located in the gastric antrum, in $17(16.2 \%)$ in the gastric body, in $25(23.8 \%)$ in the gastric fundus, and in 39 (37.1\%) in the esophagus. As shown in table 1 , there was no statistically significant difference in age, sex or location of the lesions between the GA and control groups ( $p>0.05)$. The mean diameter of the lesions was also similar between the two groups ( $\mathrm{p}>$ 0.05).

In the control group, the ESD procedures were temporarily interrupted in 35 (59.30\%) patients during the procedure to address patient's body movement, nausea, pain or general discomfort. There was no interruption during the procedure in the GA group, and the mean (42.5 \pm 5.5
Table 2. Patient satisfaction ratings

\begin{tabular}{llll}
\hline & GA $(\mathrm{n}=46)$ & Control $(\mathrm{n}=59)$ & $\mathrm{p}$ \\
\hline $0-2$ & 0 & $10(16.9)$ & 0.002 \\
$3-5$ & 0 & $11(18.6)$ & 0.002 \\
$6-8$ & $7(15.2)$ & $26(44.1)$ & 0.002 \\
$>8$ & $37(80.4)$ & $12(20.3)$ & 0.0001 \\
\hline
\end{tabular}

Figures in parentheses are percentages.

min) procedural time in the GA group was shorter than in the control group ( $79 \pm 32.2 \mathrm{~min}, \mathrm{p}=0.01$ ), while the complete removal rate was higher in the GA group ( 97.8 vs. $81.0 \%$, table $1, \mathrm{p}=0.001$ ). The postprocedural hospital stay in the control group was longer than in the GA group $(\mathrm{p}=0.03$, table 1$)$.

\section{Complications}

There were no perioperative mortalities, hypotension or respiratory depression in the control or GA group. In the control group, gastric perforation occurred in 2 (3.4\%) patients during the ESD of gastric fundus tumors. These 2 patients were successfully treated by surgery. ESD was not successful in 3 patients with esophageal dysplasia, which was subsequently removed by EMR. In another 6 patients, gastric lesions were removed by surgery after failed ESD attempts. Postprocedural gastric bleeding oc- 
curred in 7 (11.9\%) patients, and 3 of these gastric bleedings required endoscopic cauterization.

In the GA group, there were no GA-specific adverse effects such as adverse drug reactions or intubation complication. Gastric perforation occurred in $1(2.2 \%)$ patient after ESD removal of an antrum lesion. The perforation was successfully clipped during the procedure and the patient had a full recovery. Postprocedural gastric bleeding was noted in 1 patient, who was subsequently treated conservatively. The combined gastric perforation and postprocedural bleeding rate in the GA group (4.4\%) was lower than in the control group (17.0\%), but the difference did not reach statistical significance $(\mathrm{p}=0.06)$.

\section{Patient Satisfaction Ratings of the ESD Procedures}

In the control group, 11 (35.6\%) patients rated the ESD experience as unsatisfactory as a result of the discomfort or pain from the procedure as shown in table 2. Twelve (20.3\%) patients rated the experience as very satisfactory (score $>8$ ). In the GA group, all patients gave a satisfactory rating, and $37(80.4 \%)$ rated the experience as very satisfactory (score $>8$ ).

\section{Follow-Up Results}

Ninety-eight (93.3\%) patients completed a 12-month follow-up. In the control group, gastric cancer recurred in 2 patients 3 months following the ESD treatment. The lesions were removed by EMR and no recurrence was found after an endoscopic follow-up in the subsequent 12 months. One patient in the control group experienced major gastric bleeding 9 days after the ESD removal of a fundus lesion. This patient required surgical ligation of a small bleeding artery in the gastric fundus. In the GA group, no recurrent lesions were identified. However, in 2 patients, esophageal stenosis was found 4 weeks after ESD removal of an esophageal lesion. The stenosis in these 2 patients was successfully treated by balloon dilation.

\section{Discussion}

The main findings of the present study were that the procedural times of the GA group were shorter than those of the control group. More importantly, all patients in the GA group were satisfied with the ESD procedure, whereas in the control group, only $65 \%$ of the patients were happy with ESD. In addition, the postprocedural hospital stay in the GA group was shorter than in the control group, largely due to the higher number of patients with postprocedural bleeding or perforation. Also, ESD under general anesthesia reduced the procedural times and caused minimal or no pain or discomfort during the removal of esophageal or gastric carcinomas. These results indicate that ESD under general anesthesia is feasible and safe.

The mean procedural times in the GA group were 36 min shorter than in the control group. There are a number of reasons for these significantly shortened procedural times when ESD was performed under general anesthesia.

A recent study showed that with gastric tumors, location in the upper third of the stomach, tumor size greater than $20 \mathrm{~mm}$, submucosal fibrosis, and perforation during the procedure were independent predictors of a longer procedure time $[7,8]$. In the present study, the control and GA group were comparable in terms of the types, locations and the sizes of the lesions. However, more patients in the control group than in the GA group had gastric perforation, which may have contributed to a longer procedural time in the control group. Another factor contributing to the longer procedural time in the control group is that when ESD was performed with midazolam sedation only, the operations were sometimes interrupted to address patient's body movements, nausea, or general discomfort. These issues did not exist in the GA group.

In the present study, the periprocedural rates of major complications, such as perforation and bleeding requiring surgical or endoscopic intervention, were consistent with other reports [4-11], where a perforation rate between 4 and $10 \%$, and a bleeding rate of approximately $10 \%$ have been described. In our study, there was a trend towards a higher combined perforation and bleeding rate in the control group than in the GA group (17.0 vs. 4.4\%). However, the difference in the complication rate between control and GA groups did not reach statistical significance.

The short- and medium-term outcomes following ESD removal of esophageal or gastric lesions appear favorable. In the present study, 98 (93.3\%) of the 105 patients completed a 12-month endoscopic follow-up. Recurrent gastric lesions were detected in only $2 \%$ of the patients 3 months following the ESD procedure. Other large clinical observations also reported low recurrence rates from 0.9 to $2 \%$ following ESD removal of gastric or esophageal cancers $[4,7,12]$. The predicting factors for local recurrence are unclear, but incomplete resection and larger tumor size seem to increase the recurrence risk [12]. Therefore, meticulous follow-up including endoscopic examination is essential following ESD resection of all esophageal or gastric lesions. 


\section{Conclusion}

This prospective observation demonstrated that ESD under general anesthesia was associated with a shorter procedure time and a high rate of patient satisfaction with the procedures. However, as general anesthesia requires additional facilities and expertise to the standard ESD procedures under pharmacological sedation, its cost-effectiveness requires further investigation.

\section{References}

1 Ahmed N: Coevolution and adaptation of Helicobacter pylori and the case for 'functional molecular infection epidemiology'. Med Princ Pract 2011;20:497-503.

$\checkmark 2$ Retana A, Silverstein T, Wassef W: An update in endoscopic management of gastric cancer. Curr Opin Gastroenterol 2011;27:576-582.

-3 Othman MO, Wallace MB: Endoscopic mucosal resection (EMR) and endoscopic submucosal dissection (ESD) in 2011, a Western perspective. Clin Res Hepatol Gastroenterol 2011;35:288-294.

4 Park YM, Cho E, Kang HY, Kim JM: The effectiveness and safety of endoscopic submucosal dissection compared with endoscopic mucosal resection for early gastric cancer: a systematic review and metaanalysis. Surg Endosc 2011;25:2666-2677.

5 Yamagata T, Hirasawa D, Fujita N, Suzuki T, Obana T, Sugawara T, Ohira T, Harada Y, Maeda Y, Koike Y, Suzuki K, Noda Y: Efficacy of propofol sedation for endoscopic submucosal dissection (ESD): assessment with prospective data collection. Intern Med 2011; 50:1455-1460.
6 Takimoto K, Ueda T, Shimamoto F, Kojima Y, Fujinaga Y, Kashiwa A,Yamauchi H, Matsuyama K, Toyonaga T, Yoshikawa T: Sedation with dexmedetomidine hydrochloride during endoscopic submucosal dissection of gastric cancer. Digest Endosc 2011;23:176181.

7 Ahn JY, Choi KD, Choi JY, Kim MY, Lee JH, Choi KS, Kim do H, Song HJ, Lee GH, Jung HY, Kim JH: Procedure time of endoscopic submucosal dissection according to the size and location of early gastric cancers: analysis of 916 dissections performed by 4 experts. Gastrointest Endosc 2011;73:911-916.

-8 Nagata S, Jin YF, Tomoeda M, Kitamura M, Yuki M, Yoshizawa H, Kubo C, Ito Y, Uedo $\mathrm{N}$, Ishihara R, Iishi H, Tomita Y: Influential factors in procedure time of endoscopic submucosal dissection for gastric cancer with fibrotic change. Digest Endosc 2011;23:296301.
9 Lee $\mathrm{H}$, Yun WK, Min BH, Lee JH, Rhee PL, Kim KM, Rhee JC, Kim JJ: A feasibility study on the expanded indication for endoscopic submucosal dissection of early gastric cancer. Surg Endosc 2011;25:1985-1993.

10 Uedo N, Iishi H, Tatsuta M, Ishihara R, Higashino K, Takeuchi Y, Imanaka K, Yamada T, Yamamoto S, Yamamoto S, Tsukuma H, Ishiguro S: Long-term outcomes after endoscopic mucosal resection for early gastric cancer. Gastric Cancer 2006;9:88-92.

-11 Oka S, Tanaka S, Kaneko I, Mouri R, Hirata M, Kanao H, Kawamura T, Yoshida S, Yoshihara M, Chayama K: Endoscopic submucosal dissection for residual/local recurrence of early gastric cancer after endoscopic mucosal resection. Endoscopy 2006;38:996-1000.

12 Park JC, Lee SK, Seo JH, Kim Y, Chung H, Shin SK, Lee YC: Predictive factors for local recurrence after endoscopic resection for early gastric cancer: long-term clinical outcome in a single-center experience. Surg Endosc 2011;24:2842-2849. 